\title{
Hepato-Protective Effect of Aqueous Extract of Silybum- Marianum against Carbon Tetrachloride Induced Liver Injury in Rats
}

\author{
Reda Eldemerdash ${ }^{1}$, Hussam Ahmed El-Gayar ${ }^{1}$, Samar Abdullah Salim ${ }^{2}$ Neven \\ A.Salah ${ }^{3}$, and A.F.Abdel-Aziz ${ }^{3}$ \\ ${ }^{1}$ Urology and Nephrology Center, Mansoura University, Mansoura, Egypt \\ ${ }^{2}$ Nanotechnology center, Mansoura University, Mansoura, Egypt \\ ${ }^{3}$ Biochemistry Division, Chemistry Department Mansoura University, Mansoura, Egypt
}

\begin{abstract}
It is well established that $\mathrm{CCl}_{4}$ induce liver injury in animals through production of free radicals and oxidative stress, and subsequent lipid peroxidation that propagates injury. The aim of the present study was to evaluate the effect of aqueous extract of silybum marianum (SB) plant relative to silymarin (SM) as standard drug on liver enzymes, cytochrome P450 (CYP450), and histological changes using $H \& E$ and atomic force microscope (AFM). The aqueous extract of $S B$ was prepared and the determination of total phenolic compounds in aqueous extract of silybum marianum and in silymarin standard drug was done. Results showed that $\mathrm{CCl}_{4}$ was found to induce liver injury by significant increase in alanine transaminase (ALT), aspartate amino transferase $(A S T)$, and alkaline phosphatase (ALP), malondialdehyde (MDA), and CYP450 which were confirmed using $H \& E$ and atomic force microscope $(A F M)$ while decreasing albumin $(A L B)$ and activates of glutathione $-S$ transferase (GST), glutathione reduced (GSH), superoxide dismutase (SOD), catalase (CAT), total antioxidant capacity (TAC). Whereas, treatment with aqueous extract of $S B$ as well as $S M$ drug significantly decrease ALT, AST, ALP and MDA and increased ALB, GST, GSH, SOD, CAT, TAC levels as well as decreasethe level of CYP450. In conclusion, aqueous extract of $S B$ ameliorates the toxic effects of $\mathrm{CCl}_{4}$ by its free radicalscavenging and potent antioxidant activity and can be used for the treatment of liver injury.
\end{abstract}

Keywords: Silybum marianum, Silymarin, Liver enzymes, Cytochrome P450, Atomic force microscope.

\section{INTRODUCTION}

Liver as the body's key organ of metabolism and excretion is continuously and variedly exposed to xenobiotics which makes it highly susceptible to their adverse and toxic effects. Toxins absorbed from the GI tract gain access first to the liver resulting in a variety of liver disease. Thus liver damage or hepatotoxicity ranges from acute hepatitis to hepatocellular carcinoma, through apoptosis, necrosis, inflammation, immune response, fibrosis, ischemia, altered gene expression and regeneration [1].

Variability in drug metabolism among human as well as differences in CYP450 expression, have been reported. Genetic polymorphisms, endocrine imbalance, poor diet, and environmental factors can influence the expression of CYP450s in normal human livers. Occurrence of one or more of these factors can predispose a patient to altered CYP450 metabolism and unwanted/negative consequences associated with standard doses of a drug [2][3].

Carbon tetrachloride $\left(\mathrm{CCl}_{4}\right)$ has been widely used to experimentally induce liver injury in rodents and to examine the pathogenesis of cirrhosis. An acute dose of $\mathrm{CCl}_{4}$ causes centrizonal, necrosis and steatosis [4], while chronic administration causes liver fibrosis, cirrhosis, and hepatocellular carcinoma (HCC) [5]. $\mathrm{CCl}_{4}$ mechanism impairs hepatocytes directly due to altering permeability of the plasma, lysosomal, and mitochondrial membranes. Also, highly reactive free radical metabolites are formed by the mixed function oxidase system in hepatocytes via CYP2E1, causing severe centrilobular necrosis [6].

Studies showed that reactive oxygen species (ROS) are causative factors of degenerative diseases, including some hepatopathies [7]. The over-production of ROS and therefore oxidative stress can be initiated by a variety of xenobiotics, such as acetaminophen and carbon tetrachloride $\left(\mathrm{CCl}_{4}\right)[8] . \mathrm{CCl}_{4}$ induces hepatotoxic effect via its reductive dehalogenation by CYP450 2E1 to the highly reactive trichloromethyl radical $\left(\cdot \mathrm{CCl}_{3}\right)$, which is subsequently converted into a trichloromethylperoxyl radical $\left(\cdot \mathrm{OOCCl}_{3}\right)$ in the presence of oxygen [4]. 
The extracts of the flowers and leaves of silybum marianum have been used for centuries in treating liver or spleen along with gallbladder diseases [9].The extract consists of about 65-80\% silymarin and 20-35\% fatty acids, including linoleic acid [10]. Most clinical studies were carried out with isolated silymarin and flavonolignon [11]. The safety of S. marianum herbal plant is one of the most important issues, since no health hazards or side effects are known along with the proper treatment of designed therapeutic dosages [12]. The most important derivative of silybin is silymarin (70-80\%) and their antiradical and antioxidant activity was studied by [13]. Silymarin shows the antioxidant, antiinflammatory; and anticarcinogenic properties [14]. The molecular targets of silymarin for cancer prevention is modulate the balance between cell survival and apoptosis through interference with cell cycle regulators and proteins involved in apoptosis [15].

The Silybum marianum, have an antioxidant and have been shown to exhibit anti carcinogenic, antiinflammatory, hepatoprotection and growth modulatory effects.[16] Due mainly to their diverse pharmacological properties including antioxidant and hepatoprotective activity.[17] Plant-derived natural products such as flavonoids, terpenoids, carbohydrates, tannins, saponins, steroids, proteins, amino acids and vitamin have received considerable attention[18][19]. Few literatures concerning aqueous extract Silybum marianum, so that, the effect of aqueous extract of silybum marianum (SB) plant relative to silymarin (SM) as standard drug against $\mathrm{CCl}_{4}$ induced liver damage is evaluated in this present study.

\section{MATERIALS AND MethodS}

\subsection{Animals}

Male Sprague-Dawley rats initially weighing $(180-200 \mathrm{~g})$ were obtained from the Institute of Ophthalmic Disease Research, Cairo, Egypt. They were housed in stainless steel cages in an artificially illuminated and thermally controlled room $\left(22-25^{\circ} \mathrm{C}\right.$ and $12 \mathrm{~h}$ light / dark cycle). Rats were fed on normal laboratory rodent diet and given water ad libitum for one week of acclimation prior to the experimental work. All animals received human care in compliance with the guidelines of the Animal Care and Use Committee of Mansoura University.

\subsection{Silymarin Standard Drug}

Each capsule (140mg) dissolved in $5 \mathrm{ml}$ distilled water.

\subsection{Preparation of Silybum Marianum Aqueous Extracts}

SB seeds were purchased from a local market in Mansoura City, Egypt. And extraction was performed as described by [20].

\subsection{Detection of Total Phenolic Compounds in Aqueous Extract of Silybum Marianum and in Silymarin Standard Drug}

Total phenolic content of aqueous crude extract of silybum marianum and silymarine standard drug was determined by Folin- Ciocalteu method [21].

\subsection{Experimental Protocol}

Thirty six adult male rats were allocated to one of six groups of six rats of each and subjected to the following treatments:

Control (G1) served as control and received $500 \mu$ l of saline by intraperitoneal (i.p.) injection route twice a week for 4 weeks.

$\mathrm{CCl}_{4}(\mathrm{G} 2)$ received i.p. injection of $0.5 \mathrm{mg} \mathrm{CCl} / \mathrm{kg}$ body weight twice a week for 4 weeks as described by [22].

Silymarine $+\mathrm{CCl}_{4}(\mathrm{G} 3)$ received SM at a dose $100 \mathrm{mg} / \mathrm{kg}$ b.wt.daily for 6 weeks and [23]followed by $\mathrm{CCl}_{4}$ treatment.

Silybium marianum $+\mathrm{CCl}_{4}(\mathrm{G} 4)$ received SB extractat a dose $200 \mathrm{mg} / \mathrm{kg} / \mathrm{b}$.wt.for 6 weeks [24] and followed by $\mathrm{CCl}_{4}$ treatment.

Silymarine (G5) received oral dose standard drug SM at a dose $100 \mathrm{mg} / \mathrm{kg} / \mathrm{b}$.wt. daily for 6 weeks.

Silybium marianum (G6) received oral dose of SB extract at a dose $200 \mathrm{mg} / \mathrm{kg} / \mathrm{b}$.wt. daily for 6 weeks. 
At the end of the experimental period, the rats of each treated group were fasted overnight, weighed and sacrificed under slight ether anesthesia. Blood was collected by cardiac puncture. Serum were separated by centrifugation at $860 \mathrm{xg}$ for 20min. and determination of Alanine transaminase (ALT) and aspartate transaminase (AST) were carried out using enzymatic colorimetric kits according to [25], Determination of serum alkaline phosphatase activity (ALP) was assayed by the method described by [26], Serum albumin according to [27]. After the collection of blood, the liver were rapidly excised from each animal, and washed free of blood with $0.9 \% \mathrm{NaCl}$ solution, blotted and a part of it was minced and homogenized for determination of superoxide Dismutase (SOD) [28], catalase (CAT) [29], Total antioxidant capacity (TAC) [30], reduced glutathione (GSH) [31], glutathione S-transferase (GST) [32] , Malondialdehyde (MDA) [33] determination. Another part of liver was washed in $0.9 \%$ saline, minced and homogenized, for determination of cytochrome P450 enzyme using semiquantitative (RT-PCR ARKTIK, thermal cycler, USA).

\subsection{Semi-Quantitative RT-PCR Of CYP450}

To determine the effects of aqueous extract SB and SM drug on hepatic cytochrome P450 at gene level, semi-quantitative RT-PCR was determined. The specific oligonucleotide primers were shown in Table 1. Briefly, total RNA was extracted from tissue with TRIzol reagent according to the manufacturer's instructions (Invitrogen Corporation, Grand Island, NY, USA). Reverse transcription was done using $1 \mu \mathrm{g}$ of total RNA and a cDNAkit (high-capacity cDNA archive kit, USA). Two $\mu \mathrm{l}$ of the cDNA sample was mixed with 25 picoMole of each primer and $12.5 \mu \mathrm{l}$ of Taq PCR (master mix kit, QIAGEN Inc, Valencia, CA, USA). Distilled water was added to a volume of $25 \mu \mathrm{l}$, and the resulting mixture was subjected to PCR amplification (BioRad Thermal Cycler, USA). The cycling parameters were as follows: initial denaturation at $95^{\circ} \mathrm{C}$ for 5 minutes, followed by 30 cycles of $95^{\circ} \mathrm{C}$ for 30 seconds, annealing at $58^{\circ} \mathrm{C}$ for 30 seconds, elongation at $72^{\circ} \mathrm{C}$ for 30 seconds, and final extension at $72^{\circ} \mathrm{C}$ for 10 minutes. The resulting products were electrophoresed in a $1 \%$ agarose gel to detect gene bands. The signal intensity of the bands was measured using BioRad Gel Documentation model (universal hood2, USA) software and the changes in expression were normalized to GAPDH control.

Table1. The primer sequences used for real time PCR assay in rats

\begin{tabular}{|l|l|l|l|}
\hline \multicolumn{1}{|c|}{ Full name of the gene } & \multicolumn{1}{|c|}{ Sequences (5'-3') } & Accession No. & $\begin{array}{c}\text { PCR } \\
\text { Products }\end{array}$ \\
\hline $\begin{array}{l}\text { Glyceraldehyde-3-phospate } \\
\text { dehydrogenase(GAPDH) }\end{array}$ & $\begin{array}{l}\text { F: TGACTTCAACAGCAACTCCCAT } \\
\text { R: AGGGCCTCTCTCTTGCTCTC }\end{array}$ & NM_017008.4 & $211 \mathrm{bp}$ \\
\hline $\begin{array}{l}\text { Cytochrome P450, family 2, } \\
\text { subfamily c, polypeptide 22 } \\
\text { (CYP 450) }\end{array}$ & $\begin{array}{l}\text { F: GTCAGCCAAGGGTTAGGCAT } \\
\text { R: ACGGGGACCCATTGGTTTTT }\end{array}$ & NM_138512.1 & $175 \mathrm{bp}$ \\
\hline
\end{tabular}

\subsection{Histopathological Examination}

The liver tissues, fixed in $10 \%$ formalin, was dehydrated through the ascending series of ethyl alcohol (50-100), cleared in xylene, infiltrated and embedded in paraffin wax. Transverse sections of liver were cut at thickness of $5 \mu \mathrm{m}$ and stained with Mayer's Haematoxylin and Eosin (H\&E) stains for microscopic examination and atomic force microscope (AFM). according to [34].

\subsection{Atomic Force Microscope (AFM) Image}

AFM imaging was conducted in Nanotechnology center, Mansoura University, Mansoura, Egypt. Stiffness of the liver tissue was carried according to the method of [35]. The AFM imaging was conducted using contact mode using uncoated sharpend microlevers and sharpend tip with $10 \mathrm{~nm}$ radius NANOSUR FLEX AFM (NANOSURF AG, SWITZERLAND). For an AFM probe, silicon cantilever with spring constant of $0.2 \mathrm{~N} / \mathrm{m}$. scans were performed in air.

\subsection{Statistical Analysis}

All values are presented as mean \pm SEM. Differences were considered to be significant at $p<0.05$. One-way analysis of variance (ANOVA) and post-hoc test were used to determine differences between groups. The SPSS/PC program (version 17; SPSS, Chicago, Illiniois, USA) was used for statistical analysis [36]. 


\section{RESULTS}

The results of biochemical parameters demonstrated that the rats treated with $\mathrm{CCl}_{4}$ caused significant $(\mathrm{P} \leq 0.05)$ peroxidative damage as evidenced by liver enzymes and antioxidant defense system (table 2 , $3)$.

Table2. Serum alanine transaminase (ALT), aspartate aminotransferase (AST), and alkaline phosphatase (ALP) enzyme activity and albumin concentration $(A L B)$ in control group and in different rat groups

\begin{tabular}{|l|l|l|l|l|}
\hline Groups & \multicolumn{1}{|c|}{$\begin{array}{c}\text { ALT } \\
(\mathbf{U} / \mathbf{L})\end{array}$} & $\begin{array}{c}\text { AST } \\
(\mathbf{U} / \mathbf{L})\end{array}$ & $\begin{array}{c}\text { ALP } \\
(\mathbf{U} / \mathbf{L})\end{array}$ & $\begin{array}{c}\text { Albumin } \\
\text { (g/dl) }\end{array}$ \\
\hline G1 & $61.40 \pm 3.22^{\mathrm{a}}$ & $87.64 \pm 2.17^{\mathrm{a}}$ & $143.42 \pm 13.57^{\mathrm{a}}$ & $1.93 \pm 0.09^{\mathrm{a}}$ \\
\hline G2 & $96.30 \pm 3.96^{\mathrm{b}}$ & $169.93 \pm 4.77^{\mathrm{c}}$ & $820.88 \pm 38.95^{\mathrm{b}}$ & $1.29 \pm 0.03^{\mathrm{b}}$ \\
\hline G3 & $58.91 \pm 4.43^{\mathrm{a}}$ & $108.16 \pm 4.97^{\mathrm{a}, \mathrm{b}}$ & $458.50 \pm 28.22^{\mathrm{c}, \mathrm{d}}$ & $2.02 \pm 0.05^{\mathrm{a}}$ \\
\hline G4 & $64.91 \pm 3.10^{\mathrm{a}}$ & $132.48 \pm 6.08^{\mathrm{b}}$ & $573.85 \pm 34.41^{\mathrm{c}}$ & $1.97 \pm 0.06^{\mathrm{a}}$ \\
\hline G5 & $66.76 \pm 2.31^{\mathrm{a}}$ & $87.80 \pm 1.34^{\mathrm{a}}$ & $332.43 \pm 10.28^{\mathrm{d}}$ & $2.00 \pm 0.03^{\mathrm{a}}$ \\
\hline G6 & $68.30 \pm 2.51^{\mathrm{a}}$ & $92.99 \pm 2.45^{\mathrm{a}}$ & $337.50 \pm 23.34^{\mathrm{d}}$ & $1.88 \pm 0.05^{\mathrm{a}}$ \\
\hline
\end{tabular}

Each value represent the mean $\pm \operatorname{SEM}(n=6)$, values superscripts with different letters $(a-d)$ were significantly different at $p \leq 0.05$.

After injection of $\mathrm{CCl}_{4}$ to rats $(\mathrm{G} 2)$, significant $(\mathrm{P} \leq 0.05)$ increase in ALT, AST and ALP activity and significantly decreased in serum albumin concentration when compared with the control group (G1). Also, when standard drug SM was administered to $\mathrm{CCl}_{4}$ treated rats (G3), significantly $(\mathrm{P} \leq 0.05)$ decrease the activity of serum liver enzymes (ALT, AST, and ALP) and significantly $(\mathrm{P} \leq 0.05)$ increase the concentration of albumin when compared with the $\mathrm{CCl}_{4}$ treated rats (G1).

However, when aqueous extract of SB was administered to $\mathrm{CCl}_{4}$ treated rats (G4), significantly $(\mathrm{P} \leq 0.05)$ decrease serum ALT, AST and ALP and significantly $(\mathrm{P} \leq 0.05)$ increase serum albumin when compared with the $\mathrm{CCl}_{4}$ treated group (G1). Moreover, administration of aqueous extract of SB to rats treated with $\mathrm{CCl}_{4}(\mathrm{G} 4)$ did not show any significant change in ALT, AST or ALP activity when compared with G3.

Table3. Liver lipid peroxidation (MDA) and glutathione $-S$ - transferase (GST), glutathione reduced (GSH), superoxide dismutase (SOD), catalase (CAT) activity, and total antioxidant capacity (TAC) in control and in different treated rat groups.

\begin{tabular}{|l|c|c|c|c|c|c|}
\hline Groups & $\begin{array}{c}\text { MDA } \\
(\mathbf{n m} / \mathbf{g})\end{array}$ & $\begin{array}{c}\text { GST } \\
(\boldsymbol{\mu m o l} / \mathbf{m i n})\end{array}$ & $\begin{array}{c}\text { GSH } \\
(\mathbf{m g} / \mathbf{d l})\end{array}$ & $\begin{array}{c}\text { SOD } \\
(\mathbf{U} / \mathbf{g})\end{array}$ & $\begin{array}{c}\text { CAT } \\
(\boldsymbol{\mu m o l} / \mathbf{s e c} / \mathbf{g})\end{array}$ & $\begin{array}{c}\text { TAC } \\
(\mathbf{M m} / \mathbf{L})\end{array}$ \\
\hline G1 & $17.61 \pm$ & $0.61 \pm$ & $19.28 \pm$ & $60.00 \pm$ & $1.20 \pm$ & $1.04 \pm$ \\
& $0.65^{\mathrm{a}}$ & $0.04^{\mathrm{a}}$ & $1.18^{\mathrm{b}}$ & $3.33^{\mathrm{a}}$ & $0.08^{\mathrm{a}}$ & $0.02^{\mathrm{a}}$ \\
\hline G2 & $30.56 \pm$ & $0.16 \pm$ & $7.48 \pm$ & $22.50 \pm$ & $0.57 \pm$ & $0.81 \pm$ \\
& $1.83^{\mathrm{b}}$ & $0.01^{\mathrm{b}}$ & $0.74^{\mathrm{a}}$ & $2.04^{\mathrm{b}}$ & $0.03^{\mathrm{b}}$ & $0.04^{\mathrm{b}}$ \\
\hline G3 & $17.13 \pm$ & $0.42 \pm$ & $11.24 \pm$ & $60.00 \pm$ & $1.07 \pm$ & $1.07 \pm$ \\
& $0.19^{\mathrm{a}}$ & $0.04^{\mathrm{c}, \mathrm{d}}$ & $0.45^{\mathrm{b}}$ & $3.33^{\mathrm{a}}$ & $0.03^{\mathrm{a}}$ & $0.02^{\mathrm{a}}$ \\
\hline G4 & $17.87 \pm$ & $0.28 \pm$ & $13.54 \pm$ & $50.00 \pm$ & $0.97 \pm$ & $1.10 \pm$ \\
& $0.44^{\mathrm{a}}$ & $0.03^{\mathrm{e}}$ & $1.03^{\mathrm{a}, \mathrm{b}}$ & $6.67^{\mathrm{a}}$ & $0.04^{\mathrm{a}}$ & $0.03^{\mathrm{a}}$ \\
\hline G5 & $18.17 \pm$ & $0.47 \pm$ & $14.57 \pm$ & $56.67 \pm$ & $1.16 \pm$ & $1.07 \pm$ \\
& $0.36^{\mathrm{a}}$ & $0.05^{\mathrm{c}}$ & $0.32^{\mathrm{b}}$ & $5.58^{\mathrm{a}}$ & $0.04^{\mathrm{a}}$ & $0.01^{\mathrm{a}}$ \\
\hline G6 & $19.10 \pm$ & $0.47 \pm$ & $13.36 \pm$ & $60.00 \pm$ & $1.14 \pm$ & $1.04 \pm$ \\
& $0.75^{\mathrm{a}}$ & $0.04^{\mathrm{c}}$ & $0.40^{\mathrm{b}}$ & $3.65^{\mathrm{a}}$ & $0.03^{\mathrm{a}}$ & $0.01^{\mathrm{a}}$ \\
\hline
\end{tabular}

Each value represent the mean $\pm \operatorname{SEM}(n=6)$, values superscripts with different letters $(a-d)$ were significantly different at $p \leq 0.05$.

$\mathrm{CCl}_{4}$ treated group $(\mathrm{G} 2)$ showed significant increase $(\mathrm{P} \leq 0.05)$ in liver MDA as compared with the control (G1). On the other hand, liver GST,GSH, SOD, CAT and TAC activity were significantly decreased $(\mathrm{P} \leq 0.05)$ in rats treated with $\mathrm{CCl}_{4}$ as compared to control group (G1) (table 3 ).

In contrast, administration of aqueous extract of $\mathrm{SB}$ to $\mathrm{CCl}_{4}$ treated rats (G4), showed a significant decrease $(\mathrm{P} \leq 0.05)$ in liver MDA, while GST, GSH, SOD, CAT, and TAC activity were significantly increased $(\mathrm{P} \leq 0.05)$ as compared to $\mathrm{CCl}_{4}$ treated rats $(\mathrm{G} 2)$. Also, administration of standard $\mathrm{SM}$ to $\mathrm{CCl}_{4}$ treated rats $(\mathrm{G} 3)$ showed a significant decrease $(\mathrm{P} \leq 0.05)$ in liver MDA, while GST, GSH, SOD, $\mathrm{CAT}$, and TAC activity were significantly increased $(\mathrm{P} \leq 0.05)$ as compared to $\mathrm{CCl}_{4}$ treated rats $(\mathrm{G} 2)$. Moreover, administration of aqueous extract of $\mathrm{SB}$ to treated rats with $\mathrm{CCl}_{4}(\mathrm{G} 4)$ shows significant increase $(\mathrm{P} \leq 0.05)$ in GST activity while it did not show any significant change in liver MDA level or liver GST, SOD, CAT, and TAC activity when compared with G3. 


\subsection{Semi-Quantitative RT-PCR Of Cytochrome P450}

$\mathrm{CCl}_{4}$ is a hepatotoxic chemical that requires phase I drug metabolizing enzymes for metabolic activation. Therefore, it was important to determine the effects of aqueous extract of SB on the activity of CYP450 enzyme, so that the expression of this cytochrome was performed using semiquantitative RT-PCR of in liver. As shown in Figure (1) CYP450 was significantly $(\mathrm{P} \leq 0.05)$ increase in CYP 450 in $\mathrm{CCl}_{4}$ treated rats (G2) in comparison with the control group (G1). However, administration of aqueous extract of $\mathrm{SB}$ to $\mathrm{CCl}_{4}$ treated rats $(\mathrm{G} 4)$, significantly $(\mathrm{P} \leq 0.05)$ decrease in CYP450 when compared with $\mathrm{CCl}_{4}$ treated rats (G2). Also, when SM standard was administered to $\mathrm{CCl}_{4}$ treated rats $(\mathrm{G} 3)$, significantly $(\mathrm{P} \leq 0.05)$ decrease in the level of CYP450 enzyme when compared with the $\mathrm{CCl}_{4}$ treated rats $(\mathrm{G} 2)$. Moreover, the results revealed that there is non significant changes when comparing the group that treated with aqueous extract of SB (G4) group with the standard SM treated group (G3).

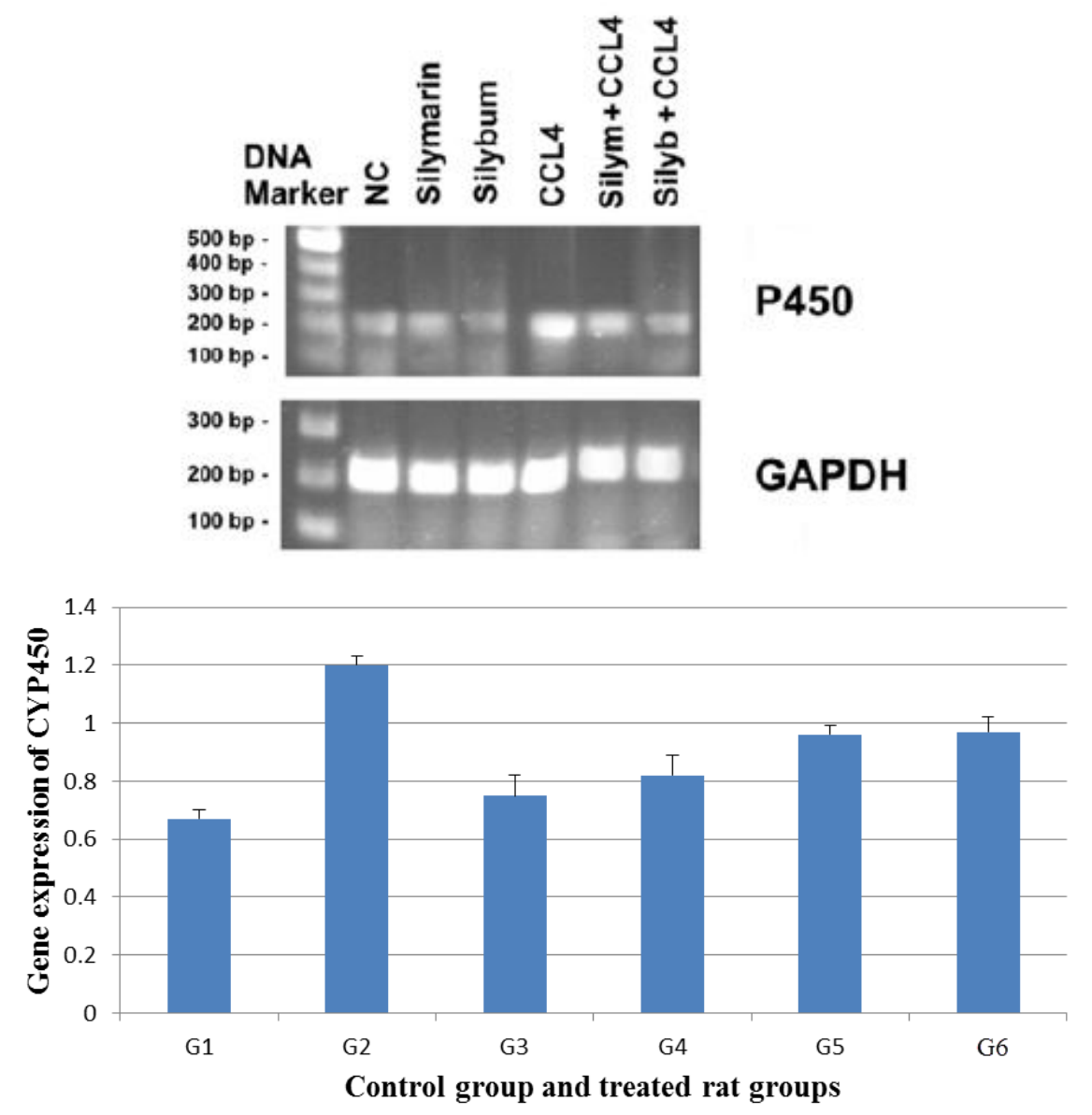

Fig1. Reverse Transcription - Polymerase Chain Reactions (RT-PCR) of P450 gene illustrates the relative expression percentages of different samples relative to negative control (100\%) by measuring the intensity of bands in agarose gel electrophoresis (semi-quantitative) by BioRad Gel Documentation model (Universal hood2, USA).

A histpathological study of liver sections of normal control (G1) rats revealed normal liver architecturenormal hepatocytes as shown in Figure (2B). Liver of $\mathrm{CCl}_{4}$ treated rats (G2) showed marked fatty change with vacuolization of hepatocytes and scattered inflammatory cells with mild fibrosis. Microscopically, examination of liver sections of rats pretreated with the aqueous extract of $\mathrm{SB}(\mathrm{G} 4)$ in a daily dose $200 \mathrm{mg} / \mathrm{kg}$ b.wt. For6 weeks in combination with $\mathrm{CCl}_{4}$ decrease the severity of histopathological changes induced by $\mathrm{CCl}_{4}$. The liver showed mild fatty change, mild fibrosis, and inflammation(Figure 2C). The liver of pretreated rats with SMin combination with $\mathrm{CCl}_{4}(\mathrm{G} 3)$ showed less fatty changes with congested veins and few inflammatory cells with no fibrosis(Figure 2D). While, histopathological examination of livers of aqueous extract of SB pretreated rats (G6) revealed normal hepatocytes (arrow) with normal radial arrangement around central vein(Figure 2E). Histopathological examination of livers of SM standard drug (G5) revealed showing normal hepatocytes (arrow) with normal radial arrangement around central vein (Figure 2F). 
Reda Eldemerdash et al.
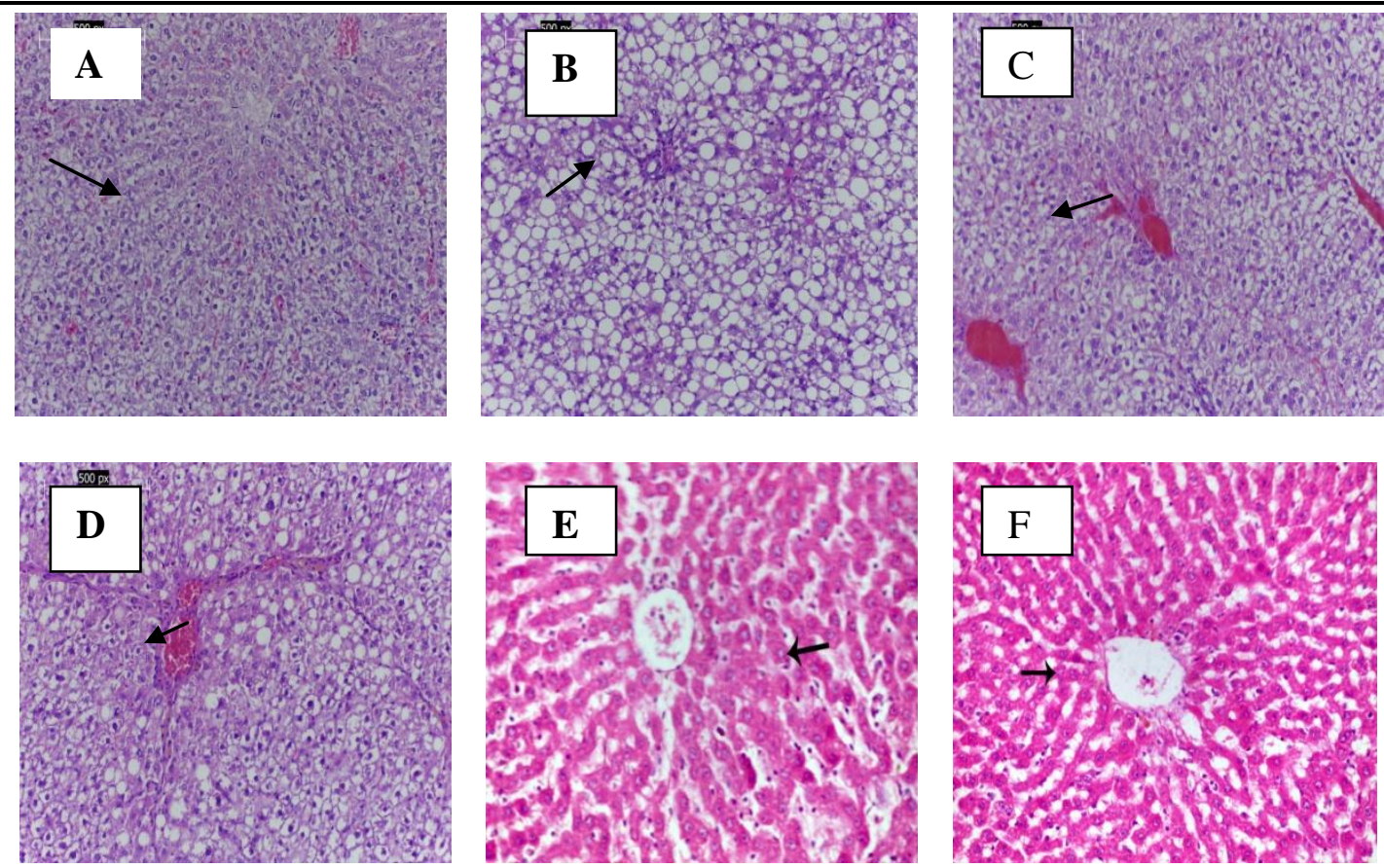

Fig2. Photomicrographs of histological sections of rat liver. A. Control showing normal liver architecture, normal hepatocytes (HE, 200x). B: $\mathrm{CCl}_{4}$ treated rats showing marked fatty change with vacuolization of hepatocytes, and scattered inflammatory cells, with mild fibrosis (HE, 200x).C: silymarine standard drug with $\mathrm{CCl}_{4}$ treatment showing less fatty changes with congested veins and few inflammatory cells with no fibrosis (HE, 200x). D: silybium with $\mathrm{CCl}_{4}$ treatment showing mild fatty changes, mild fibrosis, and inflammation .E: silymarine standard drug showing normal hepatocytes (arrow) with normal radial arrangement around central vein (HE, 400x).F: silybium marianum showing normal hepatocytes (arrow) with normal radial arrangement around central vein (HE, 400x).
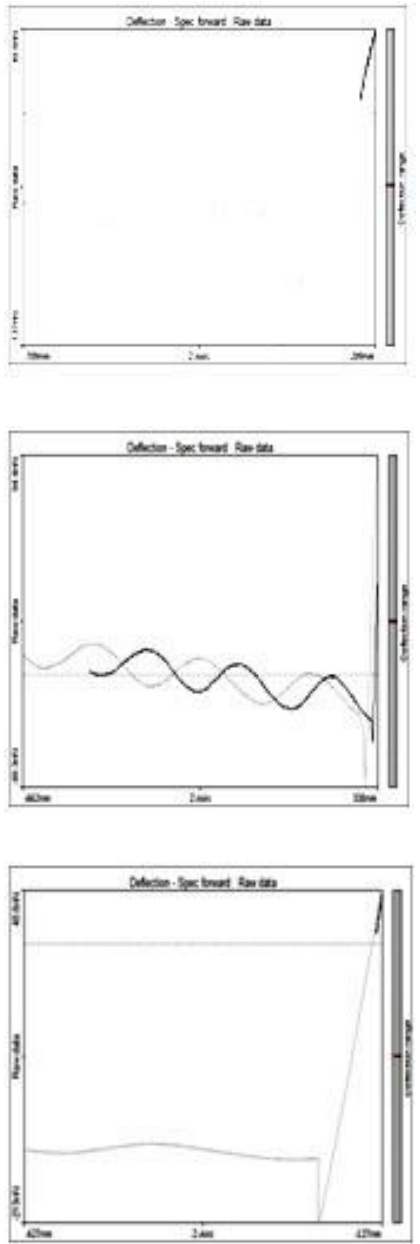

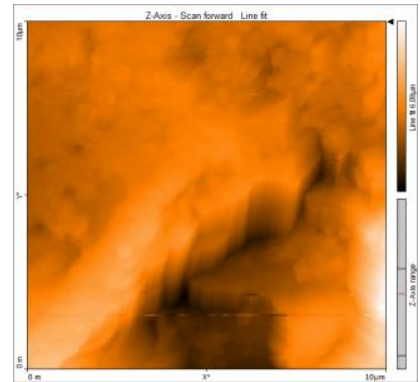

(a)

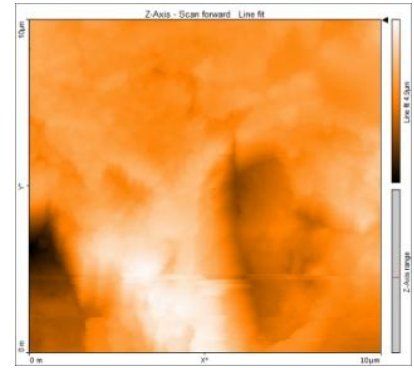

(b)

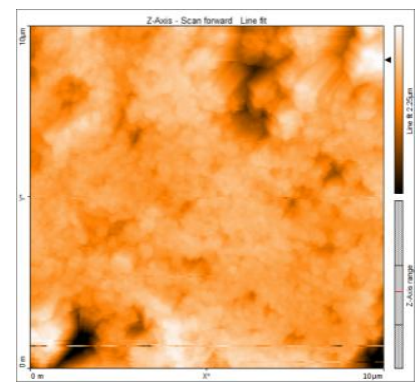

(c) 

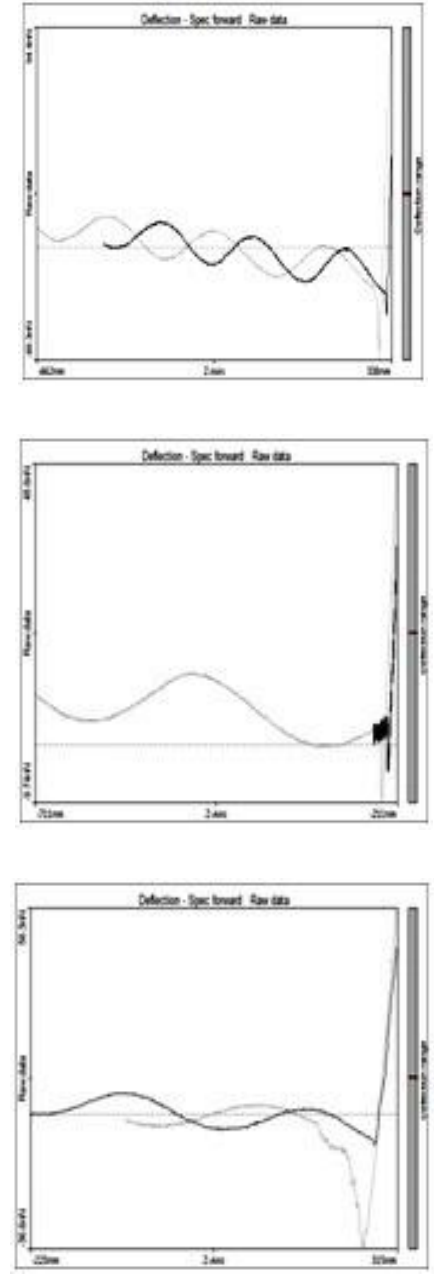

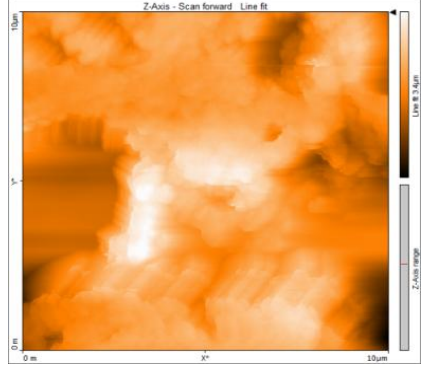

(d)

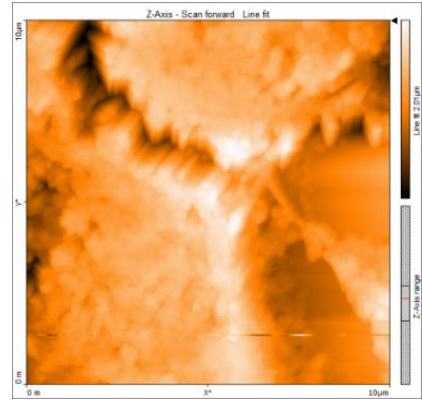

(e)

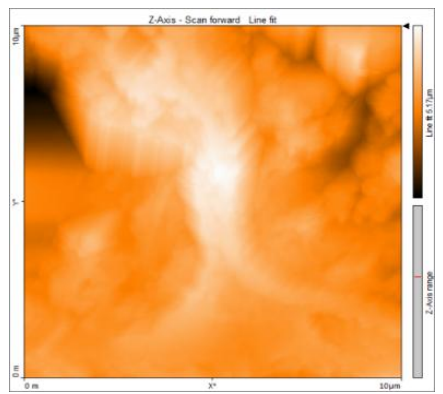

(f)

Fig3. AFM image of liver in $\mathrm{CCl}_{4}$ treated rats and in silybium (SB), silymarin (SM) treated rats, (a)force distance curve of normal liver tissue where hight $102 \mathrm{Nn}$, width $78 \mathrm{~nm}$, stiffness $1.3 \mathrm{~N} / \mathrm{m}$. (b) force distance curve of $\mathrm{CCl}_{4}$ treated rats where hight $70 \mathrm{Nn}$,width $12 \mathrm{~nm}$, stiffness $5.8 \mathrm{~N} / \mathrm{m}$, (c)force distance curve of standard drug silymarin in combination with $\mathrm{CCl}_{4}$ where hight $195 \mathrm{Nn}$, width $54 \mathrm{~nm}$, stiffness $3.6 \mathrm{~N} / \mathrm{m}$,(d)force distance curve of rats treated with aqueous extract of silybium in combination with $\mathrm{CCl}_{4}$ where hight $225 \mathrm{Nn}$, width 58nm, stiffness $3.8 \mathrm{~N} / \mathrm{m}$, (e) force distance curve of rats administered with standard drug silymarin where hight 59 $\mathrm{Nn}$, width28nm, stiffness $2.3 \mathrm{~N} / \mathrm{m}$.(f)force distance curve of rats administered with silybium where hight 59 $\mathrm{Nn}$, width $28 \mathrm{~nm}$, stiffness $2.3 \mathrm{~N} / \mathrm{m}$.

\section{DISCUSSION}

The main model to induce liver injury in animal is the administration of $\mathrm{CCl}_{4}$ [37]. Several literatures demonstrated the increased levels of serum transaminases into circulation following $\mathrm{CCl}_{4}$ exposure [38]. Administration of $\mathrm{CCl}_{4}$ results in hepatocyte damage, necrosis, inflammation, and fibrosis, which spreads to link the vascular structures that feed into and drain the hepatic sinusoid (the portal tract and central vein radicle, respectively) [39][40]. Because the changes related to $\mathrm{CCl}_{4}$-induced liver injury are similar to those of viral hepatitis [38]. In the current study, the effects of aqueous extract of silybum marianum on liver injury induced by $\mathrm{CCl}_{4}$ was investigated.

In the present study, administration of $\mathrm{CCl}_{4}$ caused a decrease in ALB compared with control group. This is in agreement with results of [41]. However, the damage effect caused by $\mathrm{CCl}_{4}$ was ameliorated with the pretreatment of aqueous extract of silybum marianum to $\mathrm{CCl}_{4}$ treated group. This result is in agreement with previous result by [42] that showed that rats treated with silybum marianum significantly increase albumin level nearly to control.

Cellular leakage and loss of the cell membrane induce elevation of serum liver enzymes [43].There was a marked elevation of serum ALT, AST, and ALP activities in $\mathrm{CCl}_{4}$ treated rats. This result is in agreement with [42] that may be due to $\mathrm{CCl}_{4}$ cause disturbance of hepatocytic transport function 
injury, causes an altered permeability of the membrane leading to the leakage of enzymes from the cells [38]. The elevation of serum liver enzymes induced by administration of $\mathrm{CCl}_{4}$ was decreased by administration of aqueous extract of silybum marianum to $\mathrm{CCl}_{4}$ treated rats, suggesting that silybum marianum has a protective effect. This might be due to antioxidant properties that effect against cellular leakage and loss of functional integrity of the cell membrane in hepatocytes.

In the present study, $\mathrm{CCl}_{4}$ induces significant elevation in the level of MDA as a marker of lipid peroxidation. This result is in agreement with previous results of [44]. This elevation of MDA may be due to $\mathrm{CCl}_{4}$ is converted into $\mathrm{CCl}_{3}$ radicals in the body via cytochrome $\mathrm{P} 450$-dependant monooxygenases. In addition to the alkylation of cellular proteins, $\mathrm{CCl}_{3}$ free radicals attack the polyunsaturated fatty acids to produce lipid peroxides that are responsible for the liver toxicity and alteration of hepatic enzyme levels [45]. Therefore, biotransformation of $\mathrm{CCl}_{4}$ results in oxidative stress and subsequent lipid peroxidation that progress liver injury [46]. The present result also indicate that treatment of $\mathrm{CCl}_{4}$ toxicated rats with aqueous extract of silybum marianum decrease the level of MDA in tissue homogenate compared with $\mathrm{CCl}_{4}$ treated group, supporting the protective role of aqueous extract of silybum marianum on hepatocytes.

One of the most important mechanism during the early stage of liver injury is GST of the $\mathrm{CCl}_{4^{-}}$ induced liver injury [47]. Conjugation of GST with GSH plays a key role in cellular detoxification of xenobiotics, electrophiles and reactive oxygen species [48].Also, GSH is an important intracellular antioxidant that spontaneously neutralizes several electrophiles and reactive oxygen species [49]. After bioactivation of $\mathrm{CCl}_{4}$, in addition to dangerous free radical formation and subsequent reactive oxygen species formation, a sequence of chain reactions can be initiated that leads to lipid peroxidation [50].

In our study the reduced level of SOD, CAT and TAC were showed. These results is in agreement with [50] whom suggest that excessive lipid peroxidation results in tissue damage and the failure of antioxidant system to ameliorate the excess production of ROS. The administration of aqueous extract of silybum marianum (SB) ameliorate all these changesby increasing the antioxidants enzymes (SOD, CAT, TAC), in addition to non- enzymatic antioxidant (GSH), and GST and subsequent reducing the MDA level in the serum, suggesting protective effect of aqueous extract of silybum marianum (SB) to scavenge the ROS to overcome the oxidative damage caused by $\mathrm{CCl}_{4}$.

CYP450 are primarily membrane-associated proteins [51] located either in the inner membrane of mitochondria or in the endoplasmic reticulum of cells. CYPs metabolize thousands of endogenous and exogenous chemicals. CYPs are the major enzymes involved in drug metabolism, accounting for about 75\% of the total metabolism [52]. Most drugs undergo deactivation by CYPs, either directly or by ease excretion from the body. Also, many substances are bio activated by CYPs to form their active compounds. Cytochrome P450 (CYP) is a phase I drug-metabolizing enzymes (DMEs) are usually involved in oxidation, reduction, or hydrolysis of chemicals including carcinogens [53].

Our results of the present study indicated that experimental liver injury induced by $\mathrm{CCl}_{4}$ caused significant increasing the level of CYP450. The enhancement effect of $\mathrm{CCl}_{4}$ on CYP450 level was also reported by several investigators [54]. This enhancement effect may be due to that $\mathrm{CCl}_{3}$ is metabolized by CYP2E1 in liver cells to produce trichloromethyl radical, trichloromethylperoxyl radical and ROS, which can cause liver damage and increase the production of fibrotic tissue [55][56].On the other hand, the results of the present study demonstrated that CYP450 was significantly normalized in the liver of treated rats with aqueous extract of SB compared with normal control. These results indicated that the restoration of CYP450 after SB treatment may be due to their regulation of CYP450 through anti-oxidative effect to affect the metabolism function of liver.

There are a number of natural hepatic protectors out there [57], but silybum marianum has shown more promise when it comes to supporting hepatic injury. Previous studies indicated the antioxidant properties of silybum marianum retarding and inhibiting the process of lipid peroxidation [58]. They reported that silybum marianum enhances hepatic glutathione and may contribute to the antioxidant defense of the liver. It has also been shown that it increases protein synthesis in hepatocytes by stimulating RNA polymerase I activity. Silybum marianum had a potent antioxidant effect due to scavenging of free radicals, superoxide anions, and oxygen radicals. Concerning the total phenolic content of aqueous extract of silybum marianum, the result of our study indicates that, the plant extract had a high content of phenolic content. Previous studies reported the potent in vivo antioxidant 
activity of silybum marianum [59]. They attributed the in vivo antioxidant activity of silybum marianum due to the increase in the level of reduced glutathione, which is an important antioxidant that detoxifies drugs and chemicals. In addition, [60] reported that silybummarianum extract produces glutathione enhancer and liver regenerator effects. These authors attributed the protective effect of silybummarianum extract against hepatotoxicity induced by carbon tetrachloride are due to the antioxidant properties of flavonoids which present in the plant. Moreover, many previous investigations proved the potent in vitro antioxidant activity of silybum marianum plant extract such as those reported by [61]; [14] and [62].

\section{CONFLICT OF INTEREST}

The authors declare no financial or commercial conflict of interest.

\section{ACKNOWLEDGEMENT}

Authors would to thank both Nile Center of Experimental Research, Mansoura, Egypt and Nanotechnology center, Mansoura University, Mansoura, Egypt for their technical and financial support

\section{REFERENCES}

[1] Anita Pathil, Arne Warth, WaleeChamulitrat, Wolfgang Stremmel, The synthetic bile acidphospholipid conjugate ursodeoxycholyllysophosphatidylethanolamide suppresses TNF $\alpha$ induced liver injury, Journal of Hepatology. 54(4), 674-684 (2011).

[2] GeorgeJ., Liddle C., Murray M., Byth K., Farrell G.C., Pre-translational regulation of cytochrome P450 genes is responsible for disease-specific changes of individual P450 enzymes among patients with cirrhosis, Biochem.Pharmacol. 49,873-881 (1995).

[3] Frye R.F., Zgheib N.K., Matzkem G.R., Chaves-Gneccom D., Rabinovitz M., Shaikh O.S., and Branch R.A., Liver disease selectively modulates cytochrome P450-mediated metabolism, Clin.Pharma.col. Ther. 80,235-245 (2006).

[4] Goeptar A.R., Scheerens H., and Vermeulen N.P., Oxygen and xenobiotic reductase activities of cytochrome P450, Crit. Rev. Toxicol. 25, 25-65 (1995).

[5] Recknagel R.O., Glende E.A. and Britton R.S., Free radical damage and lipid peroxidation, In: Meeks R.G., Harrison S.D., Bull R.J., editors. Hepato-toxicology. Boca Raton, FL: CRC Press; pp. 401-436 (1991).

[6] Recknagel R.O., Glende E.A.,Dolack J.A., and Walter R.L., Mechanism of carbon tetrachloride toxicity, Pharmacol.Ther. 43, 139-54 (1992).

[7] Hensley K., Robinson K.A.,Gabbita S.P., Salsman S., and FloydR.A.,Reactive oxygen species, cell signaling and cell injury, Free Radic. Biol. Med. 28,145_62 (2000).

[8] Ronsein G.E., Guidi D.B., Benassi J.C., Wilhelm Filho D., and Pedrosa R.C.,Cytoprotective effects of carvedilol against oxygen free radical generation in rat liver, Redox. Rep. 10, 131-137 (2005).

[9] Rainone F., Milk thistle, Am. Family Phys. 72, 1285 (2005).

[10] Kroll D. J., Shaw H. S., Oberlies N. H., Milk Thistle Nomenclature: Why It Matters in Cancer Research and Pharmacokinetic Studies, Integrative Cancer Therapies .6 (2), 110-119 (2007).

[11] Sonnenbichler J., Scalera F., and Sonnenbichler I., Stimulatory effects of silibinin and silicristin from the milk thistle Silybummarianum on kidney cells, J. Pharmacol. Exp. Ther. 290, 1375 (1999).

[12] Medical Economics Company,Milk Thistle (Silybummarianum) in PDR for Herbal Medicines,Med. Econom. Comp., Montvale, NJ.pp. 516-520(2000).

[13] Gazak R., Svobodova A., and Psotova A., Oxidized derivatives of silybin and their antiradical and antioxidant activity, Bioorgm. Med. Chem.12, 5677 (2004).

[14] Katiyar S., Silymarin and skin cancer prevention: anti-inflammatory, antioxidant and immunomodulatory effects (review),Int. J. Oncol. 26, 169 (2005).

[15] Ramasamy, K., and Agarwal, R., (2008): Multitargeted therapy of cancer by silymarin minireview. Cancer Lett., 269, 352-362. 
[16] Skottova N., Vecera R., Urbanek K., Vana P., Walterova D., and Cvak L., Effects of polyphenolic fraction of silymarin on lipoprotein profile in rats fed cholesterol-rich diets, Pharmacological Research.47, 17-26 (2003).

[17] Roy C.K., Kamath J.V., and Azad M.,Hepatoprotective activity of Psidiumguajava L leaf extract, Indian J. Exp. Biol. 44(4), 305-311 (2006).

[18] Sunttornusk L., Quantitation of Vitamin C content in herbal juice using direct titration,J.Pharm. Biomed.Anal. 28(5), 849-55 (2002).

[19] Begum S., Hassan S.I., Ali S.N., and Siddiqui B.S., Chemical constituents from the leaves of Psidiumguajava, Nat. Prod. Res. 18(2), 135-140 (2004).

[20] Elhaak M., Mohsen K., Fatma E., Mehana H.,Allelopathic potential of Silybummarianum and its utilization ability as a bio herbicide, Int.J.Curr.Microbiol.App.Sci. 3, 389-401 (2014).

[21] Blainski A., Lopes G.C., de Mello J.C., Application and analysis of the folinciocalteu method for the determination of the total phenolic content from Limonium brasiliense L, Molecules. 18(6), 6852-6865 (2013).

[22] Eidi A., Mortazavi2 P., Bazargan1 M., Zaringhalam3 J.,Hepatoprotective activity of cinnamon ethanolic extract against ccl4-induced liver injury in rats, EXCLI Journal. 11,495-507(2012).

[23] Soto C.P., Perez B.L., Favari L.P., Reyes J.L., Prevention of alloxan-induced diabetes mellitus in the rat by silymarin, Comp PharmacolToxicol. 119, 125-129 (1998).

[24] Ramadan S.I., Shalaby M.A., NehalAfifi and El-Banna H.A.,Hepatoprotective and Antioxidant Effects ofSilybummarianum Plant in Rats, IJAVMS. 5(6), 541-547 (2011).

[25] Reitman S. and Frankel A., colorimetric method for the determination of serum glutamic oxalacetic and glutamic pyruvic transaminases, Amer. J. Clin. Pathol.28,56-63 (1957).

[26] El-Aaser A., El-Merzabani M.,Simultaneous determination of 5'-nucleotidase and alkaline phosphatase activities in serum,Z. Klin. Chem. Klin. Biochem.13, 453 (1975).

[27] RodkeyF.L..Direct spectrophotometric determination of albumin in human serum.Clin. Chem. 11, 478-487 (1965).

[28] Nishikimi M., Appaji N., Yagi K., The occurrence of superoxide anion in the reaction of reduced phenazine-methosulfate and molecular oxygen,BiochemBiophys Res Commun. Jan 3146(2),8454 (1972).

[29] Aebi H., Catalase: In: Methods of enzymatic analysis analysis, Bergemeyer, H V (ed), Academic Press, New York, NY, USA. pp: 673-684 (1974).

[30] Koracevic D., K+oracevic G., Djordjevic V., Method for the measurement of antioxidant activity in human fluids, J ClinPathol. 54,356-61 (2001).

[31] Beutler E., Duron O., Kelly B., Improved for the determination of blood glutathione, J. Lab. Clin Med. 61, 882-888(1963).

[32] Harada S.H., Abei M., Tanaka N., Agarwal D., Goedde H., Liver glutathione S-transferase polymorphism in Japanese and its pharmaco-geneticimportance,Human Genetics. 75 (4), 322325(1987).

[33] Ohkawa H., Ohishi N., Yagi K., Assay for lipid peroxides in animal tissues by thiobarbituric acid reaction, Analytical Biochemistry. 95, 351-358(1979).

[34] Weesner F.M., General zoological microtechniques,Scientific Book Agency, Calcutta. P.86 (1968).

[35] Melling M., Karimian-Teherani D., Mostler S., Behnam M., Hochmeister S., 3-D morphological characterization of the liver parenchyma by atomic force microscopy and by scanning electron microscopy ,Microsc. Res. Tech. 64, 1-9(2004).

[36] Snedecor G.W., and Cochran W.G., Statistical Methods. Seventh Edition. Ames Iowa: The Iowa State University Press (1980).

[37] Lee K.J., Kim J.Y., Jung K.S., Choi C.Y., Chung Y.C., Kim D.H., Jeong H.G., Suppressive effects of Platycodongrandiflorum on the progress of carbon tetrachloride-induced hepatic fibrosis, Arch Pharm Res. 27,1238-44 (2004).

[38] Zimmerman H. J., and SeeffL. B., "Enzymes in hepatic disease," in Diagnostic Enzymology, E. L. Googly, Ed., Lea and Febiger, Philadelphia, Pa, USA, (1970). 
[39] Duvoux C., Samuel D., Hepatic transplantation, GastroenterolClin Biol.33,868-81 (2009).

[40] Alatsakis M., Ballas K.D., Pavlidis T.E., Psarras K., RafailidisS.,Tzioufa- Asimakopoulou V., Marakis G.N., Sakantamis A.K., Early propranolol administration does not prevent development of esophageal varices in cirrhotic rats,EurSurg Res. 42,11-6 (2009).

[41] Jia R1., Cao L., Du J., Xu P., Jeney G., Yin G., The protective effect of silymarin on the carbon tetrachloride $\left(\mathrm{CCl}_{4}\right)$-induced liver injury in common carp (Cyprinuscarpio), In Vitro Cell DevBiol Anim.49(3),155-61 (2013) .

[42] Tsai J.H., Liu J.Y., Wu T.T., Ho P.C., Huang C.Y., Shyu J.C., Hsieh Y.S., Tsai C.C., Liu Y.C., Effects of silymarin on the resolution of liver fibrosis induced by carbon tetrachloride in rats, J Viral Hepat. 15(7),508-14 (2008).

[43] Drotman R.B., Lawhorn G.T., Serum enzymes as indicators of chemically induced liver damage. Drug ChemToxicol.1(2),163-71 (1978).

[44] Rasool M., Iqbal J., Malik A., Ramzan H.S., Qureshi M.S., Asif M., Qazi M.H., Kamal M.A., Chaudhary A.G., Al-Qahtani M.H., Gan S.H., Karim S.,Hepatoprotective Effects of Silybummarianum (Silymarin) and Glycyrrhizaglabra (Glycyrrhizin) in Combination: A Possible Synergy,Evid Based Complement Alternat Med.2014,641597 (2014).

[45] BishayeeA., Sarkar A., and Chatterjee M., "Hepatoprotective activity of carrot (DaucuscarotaL.) againstcarbon tetrachloride intoxication in mouse liver," Journal of Ethnopharmacology.47(2), 69-74 (1995).

[46] Marques T.G., Chaib E., da Fonseca J.H., Lourenço A.C., Silva F.D., Ribeiro M.A.Jr, Galvão F.H., D'Albuquerque L.A., Review of experimental models for inducing hepatic cirrhosis by bile duct ligation and carbon tetrachloride injection,Acta Cir Bras. 27(8),589-94 (2012).

[47] Dwivedi S., Sharma R., Sharma A., Zimniak P., Ceci J.D., Awasthi Y.C., Boor PJ The course of $\mathrm{CCl}_{4}$ induced hepatotoxicity is altered in mGSTA4-4 null (-/-) mice,Toxicology. 218(1):58-66 (2006).

[48] Matés J.M., Effects of antioxidant enzymes in the molecular control of reactive oxygen species toxicology, Toxicology. 153(1-3),83-104 (2000).

[49] Lu S.C., Regulation of hepatic glutathione synthesis: current concepts and controversies, FASEB J. 13, 1169-1183 (1999).

[50] Weber L.W., Boll M. and Stampfl A., Hepatotoxicity and mechanism of action of haloalkanes: Carbon tetrachloride as a toxicological model, Crit. Rev. Toxicol. 33, 105-136 (2003).

[51] Berka K1., Hendrychová T., Anzenbacher P., Otyepka M., "Membrane position of ibuprofen agrees with suggested access path entrance to cytochrome P450 2C9 active site", Journal of Physical Chemistry. 115 (41),11248-55 (2011).

[52] Guengerich F.P., "Cytochrome p450 and chemical toxicology",Chem. Res. Toxicol. 21 (1): 7083 (2008).

[53] Cheung K.L., Kong A.N., Molecular targets of dietary phenethyl-isothiocyanate and sulforaphane for cancer chemoprevention, AAPS J. 1,87-97 (2010).

[54] Dong D., Yin L., Qi Y.,Xu L. andPeng J., Protective Effect of the Total Saponins from Rosa laevigataMichx Fruit against Carbon Tetrachloride-Induced Liver Fibrosis in Rats, Nutrients. 7, 4829-4850(2015).

[55] Tsukamoto H., Matsuoka M., French S.W., Experimental models of hepatic fibrosis: A review. Semin ,Liver Dis. 10, 56-65 (1990).

[56] Liu H., Yonghak K., Saul S., Luigi M., Yoon-Young J., In Vivo Liver Regeneration Potential of Human Induced Pluripotent Stem Cells from Diverse Origins, Science Translational Medicine. 3,82-121(2011).

[57] Salem M.B., Affes H., Ksouda K., Dhouibi R., Sahnoun Z., Hammami S., Zeghal K.M., Pharmacological Studies of Artichoke Leaf Extract and Their Health Benefits,Plant Foods Hum Nutr. (2015).

[58] Yang C.C., Fang J.Y., Hong T.L., Wang T.C., Zhou Y.E., Lin T.C., Potential antioxidant properties and hepatoprotective effects of an aqueous extract formula derived from three Chinese medicinal herbs against $\mathrm{CCl}_{4}$ induced liver injury in rats,IntImmunopharmacol. 15(1):106-13 (2013). 
[59] Shaker E., Mahmoud H., MnaaS.,Silymarin, the antioxidant component and Silybummarianum extracts prevents liver damage,Food and Chemical Toxicology. 48, 803-806(2010).

[60] Pradhan S.C. and Girish C.,Hepatoprotective herbal drugsilymarin from Silybummarianum, Ind. J. Med. Res. 124 (5), 491-504 (2006).

[61] Varga Z., Ujhelyi L., Kiss A., Balla J. and CzompaA.andAntus S., Effect of silybin on phorbolmyristate acetate-induced protein kinase $\mathrm{C}$ translocation, NADPH oxidase activity and apoptosis in human neutrophils, Phyomed. 11,206-212 (2004).

[62] Saller R., Meltzer J., Reichling J., Brignoli R. and Meier R., An updated systematic review of the pharmacology of silymarin, Forsch. Komplement Med.14 (2), 70-80 (2007). 